\title{
High Preoperative Anxiety Level and the Risk of Intraoperative Hypothermia*
}

\author{
Noriyoshi Tanaka ${ }^{1 \#,}$, Yuko Ohno ${ }^{1}$, Megumi Hori ${ }^{1}$, Mai Utada ${ }^{1}$, Kenji Ito $^{2}$, Toshiyasu Suzuki $^{2}$ \\ ${ }^{1}$ Division of Health Science, Graduate School of Medicine, Osaka University, Osaka, Japan; ${ }^{2}$ Department of Anesthesiology, School \\ of Medicine, Tokai University, Tokyo, Japan. \\ Email: "noritana@sahs.med.osaka-u.ac.jp
}

Received August $3^{\text {rd }}, 2012$; revised September 20 ${ }^{\text {th }}, 2012$; accepted October 25 ${ }^{\text {th }}, 2012$

\begin{abstract}
Aim: The relationship between preoperative anxiety level and intraoperative hypothermia $\left(<36^{\circ} \mathrm{C}\right)$ was investigated. Background: Core temperature often decreases during surgery, with an initial rapid decrease followed by a slower decrease for about 2 hours. Preoperative anxiety may influence perioperative physiological responses. The relationship between preoperative anxiety level and perioperative decrease in core temperature has not been studied closely. Design: A prospective observational study. Methods: This study enrolled 120 adult patients who underwent elective major abdominal surgery under combined epidural and general anesthesia. Tympanic membrane temperature was used to measure core temperature preoperatively and during the operation. The relationship between anxiety level according to the State-Trait Anxiety Inventory (STAI) and core temperature was examined using descriptive and multivariate risk analysis. Results: High anxiety level was found in 61 patients (51\%), of which $26(43 \%)$ developed hypothermia during the first hour and $40(66 \%)$ developed hypothermia during the first 2 hours of anesthesia. After adjustment for covariates, patients with a high anxiety level were found to have a 2.17 -fold higher risk of hypothermia during the first hour and a 1.77-fold higher risk of hypothermia during the first 2 hours than patients with a low/moderate anxiety level. Conclusions: The risk of hypothermia in the early phase of general anesthesia can be predicted by measurement of the preoperative anxiety level using the STAI. Relevance to Clinical Practice: Patients with a high anxiety level had a significantly higher risk of intraoperative hypothermia. Preoperative preventive nursing care programs should include anxiety management and thermal care.
\end{abstract}

Keywords: Anxiety; Hypothermia; Perioperative Nursing; Risk Factors; State-Trait Anxiety Inventory

\section{Introduction}

Inadvertent perioperative hypothermia remains one of the major causes of morbidity and mortality during anaesthesia [1]. Many factors related to the patient's medical history, anesthesia management, and surgery may contribute to the occurrence of hypothermia [2]. Previous studies have reported a rapid decrease in core body temperature during the first hour of anesthesia, largely due to a core-to-peripheral redistribution of body heat, followed by a slow decrease in temperature over the next few hours due to heat loss exceeding heat production [3].

It is unclear whether the patient's anxiety level affects the risk of hypothermia. Anxiety stimulates activity of the sympathetic nervous system, and probably increases the core-to-peripheral difference in temperature. The incidence of hypothermia in patients undergoing major abdominal surgery is high, and is thought to be underes-

\footnotetext{
${ }^{*}$ The authors report no conflicts of interest.

\#Corresponding author.
}

timated by $50 \%-70 \%$ [4]. Nurses giving perioperative care therefore have to manage increasing numbers of patients at high risk of perioperative hypothermia in everyday clinical practice. Most studies of perioperative hypothermia have focused on a specific population, a specific condition such as urgency of operation, or specific complications such as cardiac deaths or postoperative wound infections [5].

A method to accurately assess the risk of perioperative hypothermia during the preoperative assessment would enable nurses to give individualized patient care to reduce the risk of hypothermia. As perioperative consultations are changing from being medical-based to nursing-based, a risk assessment tool that could easily be used by nursing staff in the preoperative setting would be particularly useful.

We aimed to investigate the relationship between preoperative anxiety level and hypothermia during the early phase of anesthesia. 


\section{Methods}

\subsection{Study Participants}

This study prospectively enrolled patients undergoing elective major open abdominal surgery under combined epidural and general anesthesia, with an expected operating time of at least 2 hours, at Tokai University Hospital, Kanagawa, Japan, from April 1, 2010 to Jan 31, 2011. The study protocol was approved by the ethics committee of the hospital, and written informed consent was obtained from all patients. Inclusion criteria were: age 20 80 years, American Society of Anesthesiologists (ASA) physical status $1-3$, and surgery performed in the supine position with or without lithotomy. Exclusion criteria were: evidence of current infection, preoperative core temperature $\geq 37.5^{\circ} \mathrm{C}$, history of malignant hyperthermia, thyroid disease, dysautonomia and use of vasoactive drugs.

\subsection{Measurements}

Core temperature was measured by an earphone-type infrared tympanic membrane thermometer (CE Thermo; Nipro, Tokyo, Japan; resolution $0.01^{\circ} \mathrm{C}$, accuracy $\pm 0.1^{\circ} \mathrm{C}$ ) [6]. The ear canal was clean in all subjects, with no visible hair or cerumen. The probe was gently introduced into the right ear canal, and positioned correctly towards the tympanic membrane. The ear probe stayed in the ear canal throughout the whole time period studied. Measurements were started before the induction of anesthesia, and were continued at 15 -min intervals throughout surgery. Hypothermia was defined as core temperature < $36.0^{\circ} \mathrm{C}[7]$.

Patient anxiety level was assessed the evening before surgery using a self-reported psychological instrument, the Spielberger State-Trait Anxiety Inventory (STAI). The STAI is a validated and widely used instrument for measuring patient anxiety [8]. The STAI-state (STAI-S) form consists of 20 statements, and the patient's responses to the statements are used to determine their current anxiety level. The STAI-trait (STAI-T) form consists of a different 20 statements, and the patient's responses to the statements are used to determine their underlying (ongoing/personality) anxiety level. Each statement in the STAI-S is rated on a four-point scale according to whether the patient agrees with the statement (not at all, somewhat, moderately so, or very much so). Statements in the STAI-T are also rated on a four-point scale (almost never, sometimes, often, and almost always). The overall (total) STAI score ranges from 20 to 80 points. STAI scores are commonly classified as "no or low anxiety and moderate anxiety" (20 - 44 points), and "high anxiety" (45 - 80 points) [9]. A STAI score $\geq 45$ defines an individual as highly anxious.
The following data were collected during preoperatively: age, sex, Body mass index (BMI, body surface area (BSA), ASA physical status, history of respiratory disease, history of cardiovascular disease, diabetes mellitus, previous surgery, surgical procedure, heart rate (HR), non-invasive blood pressure (BP), and peripheral blood flow. Blood loss and urine output were measured intraoperatively.

Quantification of hemodynamic variability was accomplished by recording the HR, systolic BP (SBP), diastolic BP (DBP), and peripheral blood flow at admission, before induction of anesthesia, and after induction of anesthesia. Hemodynamic variability was calculated as a percentage according to the following equation: (before induction of anesthesia or after induction of anesthesia baseline or before induction of anesthesia)/baseline or before induction of anesthesia $\times 100$. A laser Doppler flowmeter (CyberMed CDF-2000; Libmech, Tokyo, Japan) $[10]$ was attached to the tip of the patient's thumb on the contralateral side to the non-invasive BP device to measure peripheral blood flow changes.

\subsection{Anesthetic Technique}

The anesthetic technique was standardized for each patient. No premedication was given. Active prewarming was not used. An epidural catheter was inserted via an interspace between $\mathrm{T} 8$ and $\mathrm{L} 1$ using standard techniques, and $3 \mathrm{ml}$ of $1 \%$ lidocaine was injected as a test dose. Subsequently, $6-10 \mathrm{ml}$ of $0.375 \%$ ropivacaine was injected. Epidural anesthesia was maintained during surgery with a continuous infusion of $0.2 \%$ ropivacaine with fentanyl solution $(3 \mu \mathrm{g} / \mathrm{ml})$ at a rate of $4-6 \mathrm{ml} / \mathrm{h}$, and 5 $\mathrm{ml}$ of $0.375 \%$ epidural ropivacaine was given during surgery if deemed necessary by the attending physician. General anesthesia was induced with propofol 2 - 3 $\mathrm{mg} / \mathrm{kg}$, remifentanil $0.15-0.5 \mu \mathrm{g} / \mathrm{kg} / \mathrm{min}$, and fentanyl 2 $3 \mu \mathrm{g} / \mathrm{kg}$. Rocuronium $0.6-0.9 \mathrm{mg} / \mathrm{kg}$ was given for neuromuscular blockade, and the trachea was intubated. Anesthesia was maintained with sevoflurane (minimum alveolar concentration of about 1.0), with continuous infusion of remifentanil and intermittent administration of fentanyl (total $10-30 \mu \mathrm{g} / \mathrm{kg}$ ). Mechanical ventilation using a semi-open circle system was adjusted to maintain end-tidal $\mathrm{PCO}_{2}$ at approximately $35 \mathrm{mmHg}$. Fresh gas flow was generally maintained at $2 \mathrm{l} / \mathrm{min}$. Intravenous fluids, mostly balanced electrolyte solution, were warmed to $35^{\circ} \mathrm{C}-37^{\circ} \mathrm{C}$ and infused at approximately $8-12$ $\mathrm{ml} / \mathrm{kg} / \mathrm{h}$.

All patients were warmed using a resistive heating blanket (SmartCare, Geratherm Medical AG, Germany) placed over the anterior chest and both arms from the induction of general anesthesia to the end of surgery, with the control unit set to $42^{\circ} \mathrm{C}$ [11]. Warming was 
stopped at any time the tympanic temperature was $\geq$ $37.0^{\circ} \mathrm{C}$. The resistive heating blanket cover measures $205 \times 135 \mathrm{~cm}$ and has five active warming carbon fiber elements measuring $40 \times 20 \mathrm{~cm}$ with an intermediate distance of $10 \mathrm{~cm}$, powered by a $15 \mathrm{~V}$ direct current. The operating room temperature set at $22^{\circ} \mathrm{C}-24^{\circ} \mathrm{C}$ [12] and a relative humidity of $40 \%$.

\subsection{Statistical Analysis}

Statistical analyses were performed using SPSS software version 19.0 (IBM Corporation, Chicago, IL, USA). We calculated univariate statistics using the Mann-Whitney U-test for continuous variables and Pearson's chi-squared test or Fisher's exact test for categorical variables. We used two-sided tests for all analyses, and p-values of $<0.05$ were considered to be statistically significant. We evaluated correlations between potential risk factors and the risk of hypothermia during the first hour and during the first 2 hours after induction of anesthesia. Relationships between anxiety level and potential risk factors or hypothermia were evaluated by calculation of relative risk (RR) and absolute risk reduction (ARR). Finally, logistic regression analysis was performed to determine the correlation between anxiety level and hypothermia after adjustment for the other potential risk factors. Variables with a p-value of $<0.25$ on univariate analysis were included in the multivariate logistic regression analysis. The potential risk factors included anxiety level, BMI, BSA, ASA physical status, HR variability, SBP variability, and peripheral blood flow variability.

Manipulation of variables in the model was performed using the Enter method, which forces the introduction of all the variables of interest under the specified criteria.

The study was powered to enable identification of as many as 12 variables that could predict hypothermia, requiring a sample size of 120 patients [13].

\section{Results}

It took 10 months to complete enrollment of 120 patients. The mean age of patients was 55.43 years (standard deviation 13.93 years). Table 1 shows the demographic and perioperative clinical data of the patients. Of the 120 patients, $61(51 \%)$ had a high anxiety level and $59(49 \%)$ had a low/moderate anxiety level. The preoperative patient characteristics were similar in the high anxiety and low/moderate anxiety groups, except that patients in the high anxiety group had a higher mean STAI-S score and higher mean HR. There were significant differences between the groups in HR variability, SBP variability, and peripheral blood flow variability $(\mathrm{p}<0.001$ for all).

In the high anxiety group, core temperature $<36.0^{\circ} \mathrm{C}$ occurred in 26 patients (43\%) during the first hour and in 40 patients $(66 \%)$ during the first 2 hours after induction of anesthesia. In the high anxiety group, the ARR of intraoperative hypothermia was $35.84 \%$ higher $(95 \%$ confidence interval (CI, 21.87 - 49.81) during the first hour and $41.84 \%$ higher $(95 \% \mathrm{CI}, 25.72$ - 57.97) during the first 2 hours than in the low/moderate anxiety group (RR, 3.13; 95\% CI, 1.17 - 8.34 and RR, 2.76; 95\% CI, 1.69 4.52, respectively) (Table 2).

Table 3 shows factors associated with intraoperative hypothermia. Univariate analyses showed that hypothermia during the first hour was associated with BMI (RR, $0.61 ; 95 \%$ CI, 0.38 - 0.98), ASA physical status (RR, $1.70 ; 95 \% \mathrm{CI}, 1.11-2.61)$, SBP variability (RR, 1.96; $95 \% \mathrm{CI}, 1.25$ - 3.08), HR variability (RR, 1.58 ; 95\% CI, $1.04-2.40$ ), and peripheral blood flow variability (RR, 3.68 ; 95\% CI, 2.00 - 6.79), and that hypothermia during the first 2 hours was associated with ASA physical status (RR, 1.46; 95\% CI, 1.01 - 2.12), SBP variability (RR, $1.48 ; 95 \%$ CI, 1.01 - 2.17), and peripheral blood flow variability (RR, 2.89; 95\% CI, $1.76-4.76)$.

Multivariate analyses identified high anxiety level and peripheral blood flow variability as independent predictive factors of hypothermia during both the first hour and the first 2 hours after induction of anesthesia. After adjustment for important covariates, the RR of hypothermia in patients with a high anxiety level during the first hour was $2.17(95 \% \mathrm{CI}, 1.05-4.49 ; \mathrm{p}=0.04)$ and during the first 2 hours was 1.77 (95\% CI, $1.05-2.97$; $=0.03)$.

\section{Discussion}

The results of this prospective study show that a high patient anxiety level, which is easily measured, is associated with an increased risk of hypothermia during the early phase of general anesthesia.

Preoperative anxiety and stress are common in patients awaiting surgical procedures [14]. The stress response in humans is an important method of adapting to altered environmental conditions, and is a prerequisite for responding to potential threats [15]. Hemodynamic stress responses such as increased $\mathrm{HR}$ and arterial pressure are triggered by endocrine regulatory mechanisms and the autonomic nervous system, and involve secretion of corticotropin releasing hormone, adrenocorticotropic hormone, cortisol, epinephrine, norepinephrine, dopamine, prolactin, cytokines, tumor necrosis factor-alpha, and acute phase proteins [15]. We found that patients with a high anxiety level before induction of anesthesia had a significantly higher HR and SBP, and lower peripheral blood flow, than patients with a moderate/low anxiety level, which is consistent with the findings of previous studies [16]. During general anesthesia, core hypothermia develops in three distinct phases, each of which has a different primary etiology. The initial phase results largely from the core-to-peripheral redistribution of body heat 
Table 1. Patient characteristics.

\begin{tabular}{|c|c|c|c|}
\hline & $\begin{array}{l}\text { Low/moderate anxiety } \\
(\mathrm{STAI} \leq 44, \mathrm{n}=59)\end{array}$ & $\begin{array}{c}\text { High anxiety } \\
(\mathrm{STAI} \geq 45, \mathrm{n}=61)\end{array}$ & $\mathrm{p}$-value \\
\hline \multicolumn{4}{|l|}{ Demographics } \\
\hline Sex, No. of patients & & & 0.47 \\
\hline Men & $32(54)$ & $28(46)$ & \\
\hline Women & $27(46)$ & $33(54)$ & \\
\hline Age, years & $55.92(13.66)$ & $54.97(14.29)$ & 0.71 \\
\hline Weight, kg & $161.61(8.74)$ & $161.90(7.97)$ & 0.60 \\
\hline Height, cm & $57.60(7.97)$ & $57.08(7.68)$ & 0.92 \\
\hline $\mathrm{BMI}, \mathrm{kg} / \mathrm{m}^{2}$ & $22.05(2.68)$ & $21.74(2.18)$ & 0.79 \\
\hline $\mathrm{BSA}, \mathrm{m}^{2}$ & $1.60(0.14)$ & $1.60(0.14)$ & 0.85 \\
\hline Operative site, No. of patients & & & 0.09 \\
\hline Liver & $4(7)$ & $3(5)$ & \\
\hline Colon & $19(32)$ & $11(18)$ & \\
\hline Uterus & $31(53)$ & $33(54)$ & \\
\hline Physical status score, No. of patients & & & 0.13 \\
\hline ASA I & $30(51)$ & $22(36)$ & \\
\hline ASA II & $23(39)$ & $35(57)$ & \\
\hline ASA III & $6(10)$ & $4(7)$ & \\
\hline \multicolumn{4}{|l|}{ History, No. of patients } \\
\hline Previous surgery & $23(39)$ & $31(51)$ & 0.21 \\
\hline Respiratory disease & $4(7)$ & $3(5)$ & 0.72 \\
\hline Cardiovascular disease & $11(19)$ & $16(26)$ & 0.38 \\
\hline Diabetes mellitus & $9(15)$ & $7(11)$ & 0.60 \\
\hline Trait anxiety (STAI-T) & $33.66(20-50)$ & $37.51(20-74)$ & 0.06 \\
\hline \multicolumn{4}{|l|}{ Perioperative values } \\
\hline \multicolumn{4}{|l|}{ Baseline clinical data } \\
\hline Systolic blood pressure, $\mathrm{mmHg}$ & $118.41(12.99)$ & $115.16(11.86)$ & 0.23 \\
\hline Diastolic blood pressure, $\mathrm{mmHg}$ & $70.88(8.05)$ & $68.23(9.83)$ & 0.09 \\
\hline Heart rate, beats/min & $67.64(8.55)$ & $69.00(7.61)$ & 0.32 \\
\hline \multicolumn{4}{|l|}{ Before induction of anesthesia } \\
\hline Systolic blood pressure, $\mathrm{mmHg}$ & $138.00(17.75)$ & $140.21(17.11)$ & 0.48 \\
\hline Diastolic blood pressure, $\mathrm{mmHg}$ & $79.68(10.47)$ & $78.16(11.19)$ & 0.46 \\
\hline Heart rate, per beats/min & $76.66(10.16)$ & $83.79(9.41)$ & $<0.001$ \\
\hline \multicolumn{4}{|l|}{ Hemodynamic variability } \\
\hline Systolic blood pressure, $\mathrm{mmHg}$ & $16.64(9.09)$ & $21.82(0.09)$ & $<0.01$ \\
\hline Diastolic blood pressure, $\mathrm{mmHg}$ & $12.74(11.69)$ & $15.07(0.11)$ & 0.18 \\
\hline Heart rate, per beats/min & $13.54(9.24)$ & $21.90(0.11)$ & $<0.001$ \\
\hline \multicolumn{4}{|l|}{ Peripheral blood flow } \\
\hline Before induction of anesthesia, $\mathrm{ml} / \mathrm{min} / 100 \mathrm{~g}$ & $18.26(2.89)$ & $15.29(2.44)$ & $<0.001$ \\
\hline After induction of anesthesia, $\mathrm{ml} / \mathrm{min} / 100 \mathrm{~g}$ & $32.47(3.40)$ & $32.43(3.52)$ & 1.00 \\
\hline \multicolumn{4}{|l|}{ Blood loss } \\
\hline $1 \mathrm{~h}$ after induction, $\mathrm{ml}$ & $61.63(179.23)$ & $43.61(73.14)$ & 0.53 \\
\hline $2 \mathrm{~h}$ after induction, $\mathrm{ml}$ & $234.88(282.62)$ & $219.66(231.91)$ & 0.86 \\
\hline \multicolumn{4}{|l|}{ Urine output } \\
\hline $1 \mathrm{~h}$ after induction, $\mathrm{ml}$ & $124.53(140.18)$ & $87.89(83.27)$ & 0.35 \\
\hline $2 \mathrm{~h}$ after induction, $\mathrm{ml}$ & $205.75(196.96)$ & $217.00(190.34)$ & 0.55 \\
\hline
\end{tabular}




\begin{tabular}{cllc}
\hline Core temperature & & & \\
Before induction of anesthesia, ${ }^{\circ} \mathrm{C}$ & $36.80(0.23)$ & $36.83(0.24)$ & 0.44 \\
$1 \mathrm{~h}$ after induction, ${ }^{\circ} \mathrm{C}$ & $36.30(0.21)$ & $36.10(0.28)$ & $<0.001$ \\
$2 \mathrm{~h}$ after induction, ${ }^{\circ} \mathrm{C}$ & $36.12(0.25)$ & $35.82(0.26)$ & $<0.001$ \\
\hline
\end{tabular}

Data are mean (SD) and [range], or number (\%). ASA, American Society of Anesthesiologists; BMI, body mass index; BSA, body surface area; STAI, Spielberger State-Trait Anxiety Inventory; Hemodynamic variability: (before induction of anesthesia - baseline)/baseline $\times 100$; Peripheral blood flow variability: (after induction of anesthesia - before induction of anesthesia)/after induction of anesthesia $\times 100$.

Table 2. Comparison of outcomes between high anxiety and low/moderate anxiety groups.

\begin{tabular}{cccc}
\hline & $\begin{array}{c}\text { Low/moderate anxiety } \\
(\mathrm{STA} \mathrm{I} \leq 44, \mathrm{n}=59)\end{array}$ & $\begin{array}{c}\text { High anxiety } \\
(\mathrm{STAI} \geq 45, \mathrm{n}=61)\end{array}$ & ARR (95\% CI) \\
\cline { 2 - 4 } No. of patients $(\%)$ & $4(7)$ & $26(43)$ & $35.84(21.87-49.81)$ \\
$\begin{array}{c}\text { Core Temperature }<36.0^{\circ} \mathrm{C}, \\
1 \mathrm{~h} \text { after induction of anesthesia } \\
\begin{array}{c}\text { Core Temperature }<36.0^{\circ} \mathrm{C}, \\
2 \mathrm{~h} \text { after induction of anesthesia }\end{array}\end{array}$ & $14(24)$ & $40(66)$ & $41.84(25.72-57.97)$ \\
\hline
\end{tabular}

Data are given as number (\%); CI, confidence interval; ARR, absolute risk reduction.

Table 3. Factors associated with intraoperative hypothermia (adjusted and unadjusted analyses).

\begin{tabular}{|c|c|c|c|c|c|c|c|c|}
\hline & \multicolumn{4}{|c|}{$\begin{array}{l}1 \mathrm{~h} \text { after induction of anesthesia } \\
\qquad \mathrm{RR}(95 \% \mathrm{CI})\end{array}$} & \multicolumn{4}{|c|}{$\begin{array}{l}2 \mathrm{~h} \text { after induction of anesthesia } \\
\qquad \mathrm{RR}(95 \% \mathrm{CI})\end{array}$} \\
\hline & $\begin{array}{l}\text { Univariate } \\
\text { analysis }\end{array}$ & p-value & $\begin{array}{l}\text { Adjusted } \\
\text { multivariate } \\
\text { analysis }\end{array}$ & p-value & $\begin{array}{l}\text { Univariate } \\
\text { analysis }\end{array}$ & p-value & $\begin{array}{c}\text { Adjusted } \\
\text { multivariate } \\
\text { analysis }\end{array}$ & p-value \\
\hline $\begin{array}{l}\text { High anxiety } \\
(\mathrm{STAI} \geq 45)\end{array}$ & $3.13(1.17-8.34)$ & 0.01 & $2.17(1.05-4.49)$ & 0.04 & $2.76(1.69-4.52)$ & $<0.001$ & $1.77(1.05-2.97)$ & 0.03 \\
\hline Male sex & $1.14(0.61-2.12)$ & 0.83 & & & $1.08(0.73-1.60)$ & 0.72 & & \\
\hline Age, per year & $1.19(0.79-1.82)$ & 0.40 & & & $1.16(0.81-1.67)$ & 0.42 & & \\
\hline BMI, per $\mathrm{kg} / \mathrm{m}^{2}$ & $0.60(0.38-0.98)$ & 0.04 & $0.61(0.30-1.26)$ & 0.18 & $0.85(0.59-1.22)$ & 0.37 & & \\
\hline $\mathrm{BSA}$, per $\mathrm{m}^{2}$ & $0.71(0.47-1.08)$ & 0.11 & $0.68(0.37-1.26)$ & 0.22 & $0.8(0.55-1.15)$ & 0.23 & $0.74(0.47-1.15)$ & 0.18 \\
\hline ASA physical status & $1.70(1.11-2.61)$ & 0.01 & $1.59(0.88-2.88)$ & 0.13 & $1.46(1.01-2.12)$ & $<0.05$ & $1.31(0.83-2.08)$ & 0.25 \\
\hline $\begin{array}{l}\text { Heart rate, } \\
\text { per beats/min }\end{array}$ & $1.58(1.04-2.40)$ & 0.03 & $1.13(0.66-1.95)$ & 0.65 & $1.35(0.93-1.96)$ & 0.11 & $0.98(0.62-1.55)$ & 0.92 \\
\hline $\begin{array}{l}\text { Systolic blood pressure, } \\
\text { per mmHg }\end{array}$ & $1.96(1.25-3.08)$ & $<0.01$ & $1.63(0.88-3.02)$ & 0.12 & $1.48(1.01-2.17)$ & 0.04 & $1.04(0.64-1.67)$ & 0.89 \\
\hline $\begin{array}{l}\text { Peripheral blood flow, } \\
\text { per } \mathrm{ml} / \mathrm{min} / 100 \mathrm{~g}\end{array}$ & $3.68(2.00-6.79)$ & $<0.001$ & $2.15(1.01-4.58)$ & $<0.05$ & $2.89(1.76-4.76)$ & $<0.001$ & $2.03(1.10-3.75)$ & 0.02 \\
\hline Cardiovascular disease & $1.72(0.92-3.22)$ & 0.13 & $1.22(0.70-2.14)$ & 0.49 & $1.33(0.88-2.00)$ & 0.21 & $1.15(0.72-1.85)$ & 0.56 \\
\hline Diabetes mellitus & $1.30(0.58-2.90)$ & 0.54 & & & $1.13(0.66-1.93)$ & 0.79 & & \\
\hline
\end{tabular}

CI, confidence interval; RR, relative risk; ASA, American Society of Anesthesiologists; BMI, body mass index; BSA, body surface area; STAI, Spielberger State-Trait Anxiety Inventory; Hemodynamic variability: (before induction of anesthesia - baseline)/baseline $\times 100$; Peripheral blood flow variability: (after induction of anesthesia - before induction of anesthesia)/after induction of anesthesia $\times 100$. ${ }^{*}$ See Methods for a list of all variables included in the multivariate analysis.

that occurs when anesthesia inhibits tonic thermoregulatory vasoconstriction [3]. The second phase is a result of heat loss exceeding metabolic heat production, which reduces core temperature in a slow, linear fashion [17]. Finally, a core temperature plateau is reached when emergence of thermoregulatory vasoconstriction decreases cutaneous heat loss [18] and constrains metabolic heat in the core thermal compartment [19]. The extent to which redistribution decreases core temperature depends on the anesthetic-induced inhibition of tonic thermoregulatory vasoconstriction and the magnitude of the core-to-peripheral tissue temperature gradient. The core thermal 
compartment represents about half of the body mass, and the remaining mass is typically $2^{\circ} \mathrm{C}-4^{\circ} \mathrm{C}$ cooler than the core [20]. Preoperative anxiety increases the patient's catecholamine secretion, and the increased catecholamine level causes tachycardia, hypertension, and arrhythmia [21]. Cutaneous vasoconstriction is controlled by the sympathetic nervous system, via norepinephrine binding to alpha-1 receptors [22]. In the present study, increased peripheral blood flow variability was observed in patients with a high level of anxiety. The mean body temperature of the peripheral compartment therefore has a major effect on the change in core temperature due to the coreto-peripheral redistribution of temperature, and the preoperative anxiety level may predict the degree of hypothermia. Once redistribution has occurred, heat that has been distributed to the peripheral tissues cannot be recovered by the core, because heat cannot move up a temperature gradient. Relative hypothermia in patients with a high anxiety level therefore persisted during the early phase of general anesthesia. Although high anxiety level and peripheral blood flow variability were significant predictors of core hypothermia during combined epidural and general anesthesia, other variables [12] such as gender, age, BMI, BSA, ASA physical status, HR variability, SBP variability, history of cardiovascular disease, and diabetes mellitus were not predictors of change in core temperature. It is possible that the effects of age, BMI, BSA, and ASA physical status were underestimated in the current study because the range of these variables may not have been wide enough to show an effect. Intense vasodilation associated with combined epidural and general anesthesia may have resulted in rapid and significant heat loss, causing hypothermia regardless of the other factors (age, BMI, BSA, ASA physical status, HR variability, SBP variability, history of cardiovascular disease, and diabetes mellitus).

Previous studies did not evaluate the association between anxiety level and the risk of hypothermia in the clinical setting, even though it is known that thermoregulation is inhibited by anesthesia, causing redistribution of body heat between the core and the periphery [3]. Admission to hospital, particularly when undergoing surgical treatment, may be emotionally distressing [23]. The importance of giving patients information has been supported by numerous studies [24,25]. These studies demonstrated that patients who are psychologically prepared for surgery have better outcomes than those who are not adequately prepared. Redistribution of body heat between the peripheral and core compartments seems to be completed within 1 hour after the induction of general anesthesia [26]. It is therefore important for nurses to ensure that patients are physically and psychologically as well prepared for surgery as possible. Further studies are needed to evaluate nursing interventions that might prevent hypothermia during general anesthesia.

The primary limitation of this study is that the findings cannot be generalized, as only patients who underwent elective major abdominal surgery under combined epidural and general anesthesia were studied. It is not clear whether these findings are clinically relevant to patients undergoing different types of surgery, such as open thoracic or urgent surgery.

\section{Conclusion}

The relationship between preoperative anxiety level and intraoperative hypothermia $\left(<36^{\circ} \mathrm{C}\right)$ was investigated. The STAI was used to measure the anxiety level and the relation was examined with descriptive and multivariate risk analysis. High anxiety level was found in 61 patients (51\%), of which 26 (43\%) developed hypothermia during the first hour and $40(66 \%)$ developed hypothermia during the first 2 hours of anesthesia. After adjustment for covariates, patients with a high anxiety level were found to have a 2.17-fold higher risk of hypothermia during the first hour and a 1.77-fold higher risk of hypothermia during the first 2 hours than patients with a low/moderate anxiety level. The risk of hypothermia in the early phase of general anesthesia can be predicted by measurement of the preoperative anxiety level using the STAI.

\section{Relevance to Clinical Practice}

The findings of this study suggest that a high preoperative anxiety level is significantly associated with intraoperative hypothermia. It is therefore important for nurses to identify patients with a high anxiety level and spend more time with them. In addition, nurses should implement a preventive care program that includes anxiety management and thermal care. Nurses have a duty to ensure that patients admitted to hospital are as physically and psychologically prepared for surgery as possible. This can be achieved by using appropriate tools to assess anxiety, and by spending time listening to patients' concerns. Working in partnership with patients is essential for achieving good outcomes.

\section{Acknowledgements}

We thank our nursing colleagues in the operating room for their help with data collection.

\section{REFERENCES}

[1] E. M. Scott and R. Buckland, "A Systematic Review of Intraoperative Warming to Prevent Postoperative Complications," AORN Journal, Vol. 83, No. 5, 2006, pp. 1090-1113. doi:10.1016/S0001-2092(06)60120-8 
[2] S. Kongsayreepong, C. Chaibundit, J. Chadpaibool, C. Komoltri, S. Suraseranivongse, P. Suwannanonda, E. O. Raksamanee, P. Noocharoen, A. Silapadech, S. Parakkamodom, C. Pum-In and L. Sojeoyya, "Predictor of Core Hypothermia and the Surgical Intensive Care Unit," Anesthesia \& Analgesia, Vol. 96, No. 3, 2003, pp. 826-833. doi:10.1213/01.ANE.0000048822.27698.28

[3] T. Matsukawa, D. I. Sessler, A. M. Sessler, M. Schroeder, M. Ozaki, A. Kurz and C. Cheng, "Heat Flow and Distribution During Induction of General Anesthesia," Anesthesiology, Vol. 82, No. 3, 1995, pp. 662-673. doi:10.1097/00000542-199503000-00008

[4] R. M. Forstot, "The Etiology and Management of Inadvertent Perioperative Hypothermia," Journal of Clinical Anesthesia, Vol. 7, No. 8, 1995, pp. 657-674. doi:10.1016/0952-8180(95)00099-2

[5] A. Kurz, "Thermal Care in the Perioperative Period," Best Practice \& Research Clinical Anaesthesiology, Vol. 22, No. 1, 2008, pp. 39-62. doi:10.1016/j.bpa.2007.10.004

[6] A. Kiya, M. Yamakage, T. Hayase, J. Satoh and A. Namiki, "The Usefulness of an Earphone-Type Infrared Tympanic Thermometer for Intraoperative Core Temperature Monitoring," Anesthesia \& Analgesia, Vol. 105, No. 6, 2007, pp. 1688-1692. doi:10.1213/01.ane.0000289639.87836.79

[7] D. I. Sessler, "Mild Perioperative Hypothermia," New England Journal of Medicine, Vol. 336, No. 24, 1997, pp. 1730-1737. doi:10.1056/NEJM199706123362407

[8] C. D. Spielberger, R. L. Gorsuch, R. Lushene, P. R. Vagg and G. A. Jacobs, "Manual for the State-Trait Anxiety Inventory: Stai (Form Y)," Consulting Psychologists Press, Palo Alto, 1983.

[9] C. Ruffinengo, E. Versino and G. Renga, "Effectiveness of an Informative Video on Reducing Anxiety Levels in Patients Undergoing Elective Coronarography: An Rct," European Journal of Cardiovascular Nursing, Vol. 8, No. 1, 2009, pp. 57-61. doi:10.1016/j.ejcnurse.2008.04.002

[10] J. Niwayama, T. Sato, T. Kurosawa, K. Mishima, S. Takamura, H. Yazima, M. Motegi, T. Miyahara, M. Shibata and T. Sanaka, "Prediction Method for Decreases in Blood Pressure during Hemocatharsis Therapy by Arteriolar Blood Flow Measurement," Journal of Artificial Organs, Vol. 10, No. 1, 2007, pp. 36-41. doi:10.1007/s10047-006-0357-9

[11] ECRI, "Institute Upholds Recommendations on Warming Cabinet Temperatures," Risk Management Reporter, Vol. 26, No. 2, 2007, pp. 9-10.

[12] V. D. Hooper, R. Chard, T. Clifford, S. Fetzer, S. Fossum, B. Godden, E. A. Martinez, K. A. Noble, D. O’Brien, J. Odom-Forren, C. Peterson, J. Ross and L. Wilson, "Aspan's Evidence-Based Clinical Practice Guideline for the Promotion of Perioperative Normothermia: Second Edition," Journal of Perianesthesia Nursing, Vol. 25, No. 6, 2010, pp. 343-345. doi:10.1016/j.jopan.2010.10.006

[13] P. Peduzzi, J. Concato, E. Kemper, T. R. Holford and A. R. Feinstein, "A Simulation Study of the Number of Events Per Variable in Logistic Regression Analysis," Journal of Clinical Epidemiology, Vol. 49, No. 12, 1996, pp. 1373-1379. doi:10.1016/S0895-4356(96)00236-3
[14] N. H. Badner, W. R. Nielson, S. Munk, C. Kwiatkowska and A. W. Gelb, "Preoperative Anxiety: Detection and Contributing Factors," Canadian Journal of Anaesthesia, Vol. 37, No. 4, 1990, pp. 444-447. doi:10.1007/BF03005624

[15] E. Charmandari, C. Tsigos and G. Chrousos, "Endocrinology of the Stress Response," Annual Review of Physiology, Vol. 67, 2005, pp. 259-284. doi:10.1146/annurev.physiol.67.040403.120816

[16] A. M. Morin, G. Geldner, U. Schwarz, M. Kahl, H. A. Adams, H. Wulf and L. H. Eberhart, "Factors Influencing Preoperative Stress Response in Coronary Artery Bypass Graft Patients," BMC Anesthesiology, Vol. 4, No. 1, 2004, p. 7. doi:10.1186/1471-2253-4-7

[17] J. M. Hynson and D. I. Sessler, "Intraoperative Warming Therapies: A Comparison of Three Devices," Journal of Clinical Anesthesia, Vol. 4, No. 3, 1992, pp. 194-199. doi:10.1016/0952-8180(92)90064-8

[18] D. I. Sessler, J. McGuire, J. Hynson, A. Moayeri and T. Heier, "Thermoregulatory Vasoconstriction during Isoflurane Anesthesia Minimally Decreases Cutaneous Heat Loss," Anesthesiology, Vol. 76, No. 5, 1992, pp. 670-675. doi:10.1097/00000542-199205000-00002

[19] K. Belani, D. I. Sessler, A. M. Sessler, M. Schroeder, J. McGuire, B. Merrifield, D. E. Washington and A. Moayeri, "Leg Heat Content Continues to Decrease during the Core Temperature Plateau in Humans Anesthetized with Isoflurane," Anesthesiology, Vol. 78, No. 5 1993, pp. 856-863. doi:10.1097/00000542-199305000-00008

[20] D. I. Sessler, "Perioperative Heat Balance," Anesthesiology, Vol. 92, No. 2, 2000, pp. 578-596. doi: $10.1097 / 00000542-200002000-00042$

[21] C. Weissman, "The Metabolic Response to Stress: An Overview and Update," Anesthesiology, Vol. 73, No. 2, 1990, pp. 308-327. doi:10.1097/00000542-199008000-00020

[22] P. E. Pergola, D. L. Kellogg Jr., J. M. Johnson, W. A. Kosiba and D. E. Solomon, "Role of Sympathetic Nerves in the Vascular Effects of Local Temperature in Human Forearm Skin," American Journal of Physiology, Vol. 265, No. 3, 1993, pp. H785-H792.

[23] M. Mitchell, "Conscious Surgery: Influence of the Environment on Patient Anxiety," Journal of Advanced Nursing, Vol. 64, No. 3, 2008, pp. 261-271. doi:10.1111/j.1365-2648.2008.04769.x

[24] Y. Lilja, S. Ryden and B. Fridlund, "Effects of Extended Preoperative Information on Perioperative Stress: An Anaesthetic Nurse Intervention for Patients with Breast Cancer and Total Hip Replacement," Intensive and Critical Care Nursing, Vol. 14, No. 6, 1998, pp. 276-282. doi:10.1016/S0964-3397(98)80688-5

[25] L. Y. Kiyohara, L. K. Kayano, L. M. Oliveira, M. U. Yamamoto, M. M. Inagaki, N. Y. Ogawa, P. E. Gonzales, R. Mandelbaum, S. T. Okubo, T. Watanuki and J. E. Vieira, "Surgery Information Reduces Anxiety in the Pre-Operative Period," Revista do Hospital das Clinicas, Vol. 59, No. 2, 2004, pp. 51-56. doi:10.1590/S0041-87812004000200001

[26] W. C. Stevens, T. H. Cromwell, M. J. Halsey, E. I. Eger, 
2nd, T. F. Shakespeare and S. H. Bahlman, "The Cardiovascular Effects of a New Inhalation Anesthetic, Forane, in Human Volunteers at Constant Arterial Carbon Diox- ide Tension," Anesthesiology, Vol. 35, No. 1, 1971, pp. 8-16. doi:10.1097/00000542-197107000-00005 